\title{
A comparison of central aversive stimulation and peripheral shocks in the production of learned helplessness
}

\author{
ANNA ROSE CHILDRESS and EARL THOMAS \\ Bryn Mawr College, Bryn Mawr, Pennsylvania 19010
}

\begin{abstract}
Rats were given helplessness training with either inescapable peripheral shocks or inescapable, similarly aversive, central stimulation in the dorsal midbrain. The effects of helplessness treatment were assessed in an FR 3 leverpress escape task administered 1 day later. Helplessness treatment with peripheral shocks produced severe deficits in later escape to peripheral shock, but not to dorsal midbrain stimulation. Helplessness treatment with dorsal midbrain stimulation produced no deficits in later escape to either dorsal midbrain stimulation or peripheral shocks. These data pose problems for a strict cognitive model of the helplessness syndrome.
\end{abstract}

Animals given inescapable peripheral shocks later fail to escape in a test session when the aversive stimulation is escapable. This phenomenon, called "learned helplessness" (Maier \& Seligman, 1976), has been reliably demonstrated in dogs (Overmier \& Seligman, 1967), cats (Thomas \& DeWald, 1977), and rats (Seligman \& Beagley, 1975; Seligman, Rosellini, \& Kozak, 1975).

When animals are given the first few inescapable shocks, they react strongly, vocalize, jump about, and often try to escape the apparatus. This initial period of intense agitation is followed by a stage of lethargy, during which the animals exhibit a striking lack of fear or affect. Animals show little behavioral initiation, and may stand silently, virtually motionless during subsequent shock presentations (Seligman, 1975; Thomas \& DeWald, 1977).

In the course of physiological experiments unrelated to helplessness, we incidentally observed that such "helpless" symptomology was conspicuously absent in animals receiving stimulation of aversive sites in the brain. Though these animals were given many trains of central aversive stimulation, they continued to locomote and attempt escape of the apparatus. The aversive stimulation was inescapable, yet these animals did not appear "'helpless."

The present study was designed to test directly whether exposure to inescapable aversive central stimulation could result in helplessness as measured by an escape deficit. We compared, in a systematic

The research here was supported by Grant MH 27023 from the National Institute of Mental Health to the second author. Portions of the experiments reported here were presented at the Forty-Seventh Annual Meeting of the Eastern Psychological Association (1976). Requests for reprints should be sent to Earl Thomas, Department of Psychology, Bryn Mawr College, Bryn Mawr, Pennsylvania 19010. fashion, the effects of inescapable aversive peripheral shocks and similarly aversive central stimulation in the production of helplessness.

A cognitive approach to the helplessness syndrome, such as that of Seligman (1975), states that during inescapable shocks the organism learns that environmental outcomes are independent of its responses. This learning decreases the motivation to respond and results in later escape deficits. Failure to produce helplessness using inescapable aversive central stimulation would pose problems for a cognitive model which must predict that any sufficiently aversive inescapable stimulation should result in helplessness.

\section{METHOD}

Subjects

The subjects were 30 male albino rats of the Sprague-Dawley strain obtained from West Jersey Biological Supply. Animals were 120-150 days old at the time of running. All animals were maintained on ad-lib food and water.

\section{Apparatus}

The apparatus consisted of a $24 \times 24 \times 24 \mathrm{~cm}$ chamber. The floor of the chamber consisted of $.6-\mathrm{cm}$ steel grids placed at 2 -cm intervals. A retractable lever $(6.0 \times 7.5 \mathrm{~cm})$ was mounted $4 \mathrm{~cm}$ above the grid floor. The top and door of the chamber were Plexiglas, the door covered with a one-way mirror. White masking noise was delivered through a speaker mounted at the rear of the chamber. The running chamber was housed in a large sound-attenuating cubicle equipped with a houselight.

Peripheral shock was delivered between the grid floor and a subcutaneous safety-pin electrode attached to a shaved spot on the back of each animal. The electrode lead was suspended from the top of the chamber. The shock source was a Grason-Stadler constant-current shock generator.

Central stimulation was produced by a Grass S44 stimulator. Both peripheral and central stimulation were monitored by a Bionix dual channel oscilloscope.

\section{Surgery}

All 30 animals were anesthetized and implanted with the sub- 
cutaneous safety-pin electrode. While anesthetized, 20 of these animals were stereotaxically implanted with a single pair of bipolar electrodes in the central gray of the dorsal midbrain with the following coordinates: A-P 1.0, lateral .8, D-V 4.0, according to the atlas of König and Klippel (1963). Electrode plugs were attached with dental cement covering stainless steel screws anchored in the skull. All animals were allowed at least 2 days of recovery before the beginning of experimental procedures.

\section{Histology}

At the end of the experiment, all operates were sacrificed, perfused with Formalin; frozen sections were taken at $40 \mu \mathrm{m}$. Sections were analyzed by a photographic procedure similar to that of Guzman-Flores, Alcaraz, and Fernandez-Guardiola (1958).

\section{Procedure}

Seligman and Beagley (1975) have recently developed a reliable procedure for producing helplessness in the rat with peripheral shocks. The procedure, apparatus, and shock parameters in the following experiments are modeled closely after the Seligman experiments. Since previous Seligman experiments have demonstrated that helplessness occurring with the present procedure and parameters is a function of the controllability of the shock, an escapable shock group was not considered necessary for the purpose of the present experiment.

Six groups, each containing five animals, were used. Each group received 2 days of training procedures. On the 1 st day, the groups were given either helplessness training or an appropriate control procedure. On the 2 nd day, the animals received escape training. The groups differed in the kinds of aversive stimulation delivered in both the helplessness training and escape testing.

On Day 1, the 30 animals were divided into three major groups. Two of these groups received 80 trials of inescapable aversive stimulation. For Group S, inescapable aversive stimulation consisted of $1 \mathrm{~mA}$ peripheral shock delivered through the subcutaneous back electrode. The other group (DM) received inescapable aversive stimulation in the dorsal midbrain. Brain stimulation consisted of 100-pulse/sec bipolar monophasic square waves of $1 \mathrm{msec}$ duration. Current levels used ranged from .2 to $.8 \mathrm{~mA}$. At these levels, dorsal midbrain stimulation produced agitation and locomotor behavior virtually indistinguishable from that found with peripheral shock. For both groups, the duration of the inescapable aversive stimulation ( $\mathrm{S}$ or $\mathrm{DM}$ ) was $15 \mathrm{sec}$, delivered according to a variable intertrial interval of $1 \mathrm{~min}$, and in both cases the stimulation pulsated on and off five times a second, with equal on and off times of $.1 \mathrm{sec}$. The session of 80 trials lasted approximately $90 \mathrm{~min}$.

The third group of 10 animals were designated as controls (control) and simply received exposure to the experimental chamber for 90 min on Day 1.

On Day 2, all subjects were given 20 escape test trials in the same chamber. Group $S$ animals were subdivided into two groups for testing: those receiving peripheral shock (Group S/S) and those receiving dorsal midbrain stimulation (S/DM). Animals receiving dorsal midbrain stimulation on Day 1 (DM) were divided into two groups on the same basis, forming Group DM/DM and Group DM/S.

The group of control animals was similarly subdivided: half the animals were tested with peripheral shock (Group Control/S) and the other half tested with dorsal midbrain stimulation (Group Control/DM). Current levels for the animals tested with dorsal midbrain stimulation were selected in a protocol prior to the escape session.

During escape testing, a $6.0 \times 7.5 \mathrm{~cm}$ lever was present in the chamber. Three presses on this lever (FR 3) were required to terminate the aversive stimulation (peripheral shock or dorsal midbrain stimulation). If no escape occurred, maximal duration of aversive stimulation was $60 \mathrm{sec}$. Stimulus parameters and ITI were the same as those used for inescapable trials on Day 1. Both latency to escape and failures to escape were recorded.

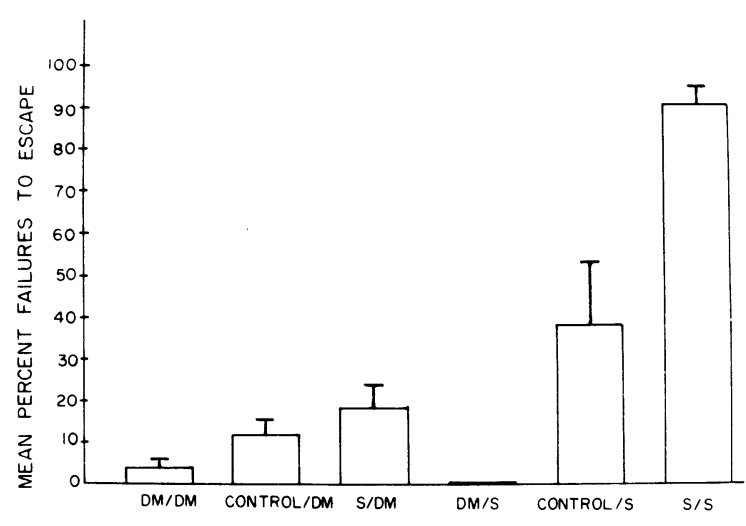

Figure 1. Mean percentage of failures to escape during test session for all groups.

\section{RESULTS}

The results depicted in Figure 1 show the data for all groups tested in terms of percentage failures to escape. A two-factor analysis of variance conducted upon the escape data yielded a significant effect of pretreatment procedure $[\mathrm{F}(2,24)=25.7, \mathrm{p}<.001]$, a significant effect of test procedure $[\mathrm{F}(1,24)=$ $24.9, \mathrm{p}<.001]$, and a significant interaction $[\mathrm{F}(2,24)$ $=13.9, \mathrm{p}<.001]$. The results described below are further comparisons using Duncan's multiple range test.

As shown in Figure 1, animals given peripheral shock during helplessness training and the escape day failed to escape on $91 \%$ of the trials. Controls given exposure to the chamber on Day 1 failed to escape on only $38 \%$ of the test trials. The difference between these two groups was significant $(p<.05)$. This result replicates the recent Seligman data (Seligman \& Beagley, 1975) on helplessness in rats produced by inescapable peripheral shock.

On the other hand, animals given dorsal midbrain stimulation on both helplessness training and test day failed to escape on only $4 \%$ of the test trials. These animals (Group DM/DM) did not differ significantly from their controls (Group Control/DM) in failures to escape.

Furthermore, animals given inescapable dorsal midbrain stimulation as helplessness training showed efficient escape behavior when later tested with peripheral shocks (Group DM/S). In fact, animals in Group DM/S showed the best escape behavior of all groups tested, and were significantly better escapers than their controls (Group Control/S), who received chamber exposure on Day $1(p<.05)$.

Finally, animals given inescapable peripheral shocks as helplessness training showed $18 \%$ failures to escape on later test trials with dorsal midbrain stimulation (Group S/DM). These animals did not differ significantly from control animals (Group Con- 


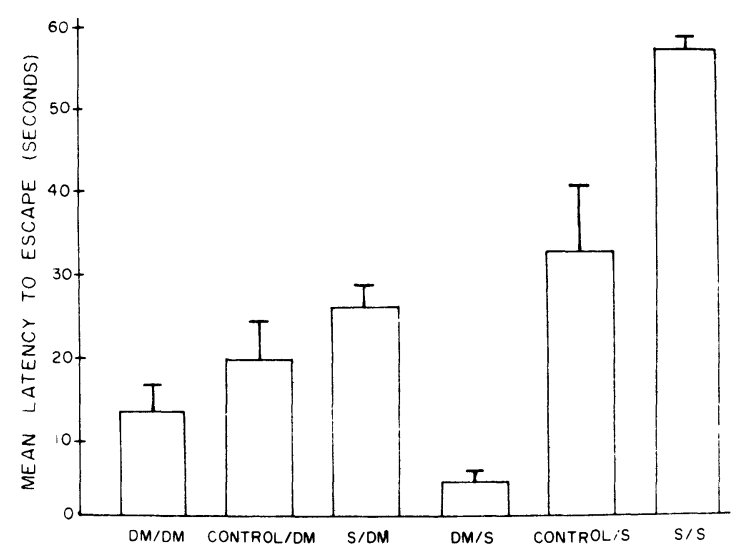

Figure 2. Mean latencies to escape during test session for all groups.

trol/DM), who only received exposure to the chamber on Day 1.

A similar analysis of variance conducted upon the latency to escape data also yielded significant effects of pretreatment procedures $[\mathrm{F}(2,24)=29.0$, $\mathrm{p}<.001]$ and test procedures $[\mathrm{F}(1,24)=12.3$, $\mathrm{p}$ $<.001]$, and a significant interaction $[F(2,24)=$ $12.0, \mathrm{p}<.001]$. Individual comparisons with Duncan's multiple range test yielded the same general pattern of results as seen in the data on failures to escape. The data for latency to escape in all groups is presented in Figure 2.

Finally, control animals tested with dorsal midbrain stimulation (Group Control/DM) did not differ significantly from controls tested with peripheral shock (Group Control/S) in latency to escape. This finding suggests that the central and peripheral stimulation were of similar aversiveness, at least as indexed by their ability to produce escape behavior.

\section{Histological Results}

Figure 3 depicts the representative placement of the implanted electrodes. As can be seen, all electrodes were in the vicinity of the central gray or nearby dorsal midbrain.

\section{DISCUSSION}

Of all the animals tested, the only group showing helplessness was that given both helplessness training and escape testing with peripheral shock. Groups receiving dorsal midbrain stimulation in training or testing, or in both, showed efficient escape behavior. Furthermore, dorsal midbrain stimulation given inescapably actually potentiated later escape to peripheral shock, producing the best escape behavior $(100 \%)$ of all groups tested. This finding stands in marked contrast to the severe shock escape deficits produced by helplessness training with peripheral shock. The same trend toward potentiation of escape behavior is seen in animals given helplessness training and testing with dorsal midbrain stimulation.

Animals given helplessness training with peripheral shocks showed the familiar lethargy and lack of affect by the end of the session. In contrast, animals given dorsal midbrain stimulation inescapably remained active throughout, and showed no symptoms of helplessness during treatment or in later test sessions. If tested with peripheral shocks, they, as their escape scores indicate, seemed even more motivated to escape than control shock animals.

It should be pointed out that the present pattern of results cannot easily be explained in terms of differences in intensity between peripheral shock and central aversive stimulation. As previously mentioned, control animals tested with dorsal midbrain stimulation (Group Control/DM) did not differ significantly from controls tested with peripheral shocks (Group Control/S) in latency to escape. Furthermore, the factorial design used in this experiment mitigates against an interpretation based on differences in intensity. Instead, the present pattern of results are best interpreted as resulting, not from differences in intensity, but from differences in the origin-central vs. peripheral-of the aversive stimulation.

The present results clearly indicate that inescapable aversive brain stimulation does not produce helplessness. Cognitive models of the helplessness syndrome (Seligman, 1975) state that the organism learns during inescapable trauma that environmental

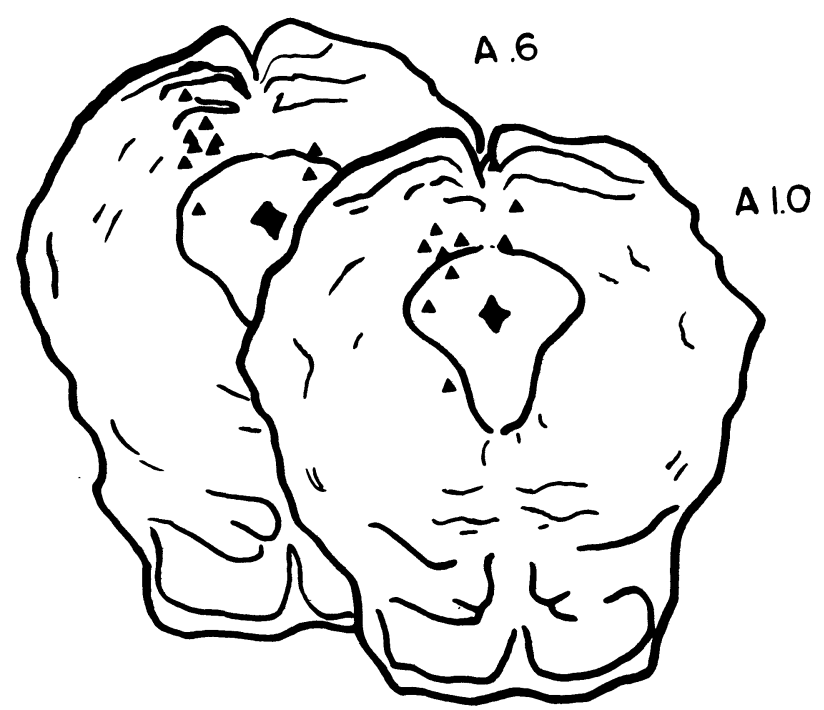

Figure 3. Representation of electrode placements, as plotted on drawings from König \& Klippel (1963). Black triangles indicate location of the electrode tip. 
outcomes are independent of its responses. This learning decreases the motivation to respond and results in later escape deficits. The present data suggest a possible restriction upon the cognitive interpretation of helplessness, in that at least certain classes of aversive stimuli do not produce the syndrome predicted by a "learned helplessness" hypothesis.

The present results appear to be consistent with recent data by Glazer and Weiss (1976a, 1976b). Glazer and Weiss found that rats showed a biphasic pattern of response to peripheral shock: at the beginning of a shock train, the animals respond by vigorous struggling, but activity decreases as the shock continues. Only shock trains long enough $(5 \mathrm{sec}$ or more) to produce an activity decrease resulted in long-term escape deficits. Though our animals showed activity decreases similar to those observed by Glazer and Weiss during peripheral shocks, animals given dorsal midbrain stimulation reacted vigorously throughout its duration-and did not become helpless.

The activity decrease that occurs during peripheral shock could reflect the onset of motivational inhibitory mechanisms triggered by inescapable stress. This interpretation is consistent with a motivational model of the helplessness syndrome, such as the one recently proposed by Thomas and DeWald (1977). According to this approach, helplessness is a pathological state of motivational inhibition triggered in response to inescapable stress. This state is characterized by a loss of affect and responsiveness to normally motivating stimuli such as shock. Forebrain inhibitory structures such as the septum may mediate the pathological inhibition seen in helplessness (Beagley \& Beagley, 1978; Thomas \& DeWald, 1977). While such inhibition is presumably generated by inescapable peripheral shock, direct stimulation in an aversive center (dorsal midbrain) efferent to the fore- brain inhibition, could remain an effective motivational stimulus. The efficient escape behavior of all groups receiving dorsal midbrain stimulation attests to the effectiveness of this stimulus.

\section{REFERENCES}

Beagley, G. H., \& Beagley, W. K. Alleviation of learned helplessness following septal lesions in rats. Physiological Psychology, 1978, 6, 241-244.

Glaze R, H. I., \& Weiss, J. M. Long-term and transitory interference effects. Journal of Experimental Psychology: Animal Behavior Processes, 1976, 2, 191-201. (a)

Glazer, H. I., \& Weiss, J. M. Long-term interference effect: An alternative to "learned helplessness." Journal of Experimental Psychology: Animal Behavior Processes, 1976, 2, 202-213. (b)

Guzman-Flores, C. M., Alcaraz, M., \& FernandezGuardiola, A. Rapid procedure to localize electrodes in experimental neurophysiology. Boletin del Instituto de Estudios Medicos Biologicos (Mexico), 1958, 16, 26-31.

KöNig, J., \& KLIPPEL, R. The rat brain: A stereotaxic atlas of the forebrain and lower parts of the brain stem. Baltimore: Williams \& Wilkins, 1963.

Maier, S. F., \& Seligman, M. E. P. Learned helplessness: Theory and evidence. Journal of Experimental Psychology: General, 1976, 105, 3-46.

Overmier, J. B., \& Seligman, M. E. P. Effects of inescapable shock upon subsequent escape and avoidance learning. Journal of Comparative and Physiological Psychology, 1967, 63, 23-33.

Seligman, M. E. P. Helplessness. San Francisco: Freeman, 1975.

Seligman, M. E. P., \& Beagley, G. Learned helplessness in the rat. Journal of Comparative and Physiological Psychology, $1975,88,534-541$.

Seligman, M. E. P., Rossellini, R., \& Kozak, M. J. Learned helplessness in the rat: Time course, immunization and reversibility. Journal of Comparative and Physiological Psychology, 1975, 88, 542-547.

Thomas, E., \& DeW Ald, L. Experimental neurosis: Neuropsychological analysis. In J. D. Maser \& M. E. P. Seligman (Eds.) Psychopathology: Experimental models. San Francisco: Freeman, 1977.

(Received for publication December 21, 1978; revision accepted April 10, 1979.) 